San Jose State University

SJSU ScholarWorks

Faculty Publications, Anthropology

Anthropology

$1-1-2002$

\title{
Trusting Strangers: Work Relationships in Four High-Tech Communities
}

Jan English-Lueck

San Jose State University, jan.english-lueck@sjsu.edu

A. Saveri

C. N. Darrah

San Jose State University

Follow this and additional works at: https://scholarworks.sjsu.edu/anth_pub

Part of the Anthropology Commons

\section{Recommended Citation}

Jan English-Lueck, A. Saveri, and C. N. Darrah. "Trusting Strangers: Work Relationships in Four High-Tech Communities" Information, Communication and Society (2002): 90-108. https://doi.org/10.1080/ 13691180110117677

This Article is brought to you for free and open access by the Anthropology at SJSU ScholarWorks. It has been accepted for inclusion in Faculty Publications, Anthropology by an authorized administrator of SJSU ScholarWorks. For more information, please contact scholarworks@sjsu.edu. 
2002 "Trusting Strangers: Work Relationships in Four High-Tech Communities," with A. Saveri and C.N. Darrah. Information, Communication and Society, 5 (1): 90-108

\title{
Trusting Strangers: Work Relationships in Four High-Tech Communities
}

\author{
J.A. English-Lueck, C. Darrah and A. Saveri
}

\begin{abstract}
Trusting Strangers: Work Relationships in Four High-Tech Communities

(J. A. English-Lueck, C. Darrah and A. Saveri)
\end{abstract}

\begin{abstract}
For the last ten years, anthropologists have been studying work, family and technology in Silicon Valley. Using intensive observation and ethnographic interviews, we have investigated the daily life of people in Silicon Valley in an ecosystem of research endeavors we have dubbed the Silicon Valley Cultures Project, supported by grants by the National Science Foundation and the Alfred P. Sloan Foundation, as well as through partnerships with the Institute for the Future. The latter collaborated to conduct ethnographic interviews on the details of work and technologically mediated communications in Bangalore, India, Dublin, Ireland, and the Taipei-Hsinchu corridor in Taiwan, revealing the complexities of global interconnections in families and workplaces. These projects have explored the penetration of work, technology and global interconnections into the daily lives of the people. We used a comparative approach, a multi-site research design, to yield different research questions. Cross-site analysis allows us to see that differing social and technical infrastructures shape the way trust is built and maintained. Locating research sites in different locations also emphasizes the problematic nature of technologically-mediated relationships, since networks built at a distance and maintained virtually have risks that locally constructed networks do not. Workers in silicon places are simultaneously inwardly-focused and embedded in a local context and connected to global economic and communications nodes. Interdependent high tech work, often using technologically mediated communication, requires a high degree of trust. The cultural construction of "trust" and the culturally situated negotiation of trust relationships need to be explored in this context. High-tech knowledge work is done by networks of interdependent
\end{abstract}


global workers that must share information, act under a severe time constraint, and establish effective relationships at a distance. The management of interpersonal and organizational expectations that is embodied in the concept "trust" is an example of how locally constructed cultural realities are enacted on a global stage.

\section{Text}

New media industries, a concept embracing such business entities as dot.coms, incubators, and other multimedia start-up companies, is part of a larger phenomenon, a "new business ecology" which is the result of two converging processes - the penetration of information technologies into work and the globalization of commerce (Institute for the Future 1999: 4-7). The resulting global high-tech work domain is composed of an ecosystem of organizations, globally linked through by technological saturated work processes. That ecosystem can be parsed in a variety of ways. It can be dissected by industry type and artificially divided into such categories as computer hardware related production, software, telecom, wireless telecom, biotechnology, and so forth. Within industries some work organizations design a mobile phone, others write the appropriate software, while yet others fund and market. The ecosystem can be classified using yet different criteria by focusing on business strategy, such a classification would separate organizations related to the industrial "old" or "new" media economies, although the merger of internet-based strategies into "brick and mortar" companies problematizes that approach. Urban planners can examine the impact of the twin forces of technofication - the specialization of the local economy around high technology — and globalization and determine if the region is a "silicon place," and how it fits into a larger web of silicon places. Those concerned with economic development in each country may be more concerned with whether a high-tech company is part of a multinational organization based elsewhere or part of an indigenous effort. Finally, the ecosystem can be viewed from the vantage point of the participants, the workers who occupy different parts of the ecosystem, bouncing from one industry to another, back and forth between new media businesses and old industrial giants. From their point of view, the view we studied, the categories listed above might be strategically invoked, but what matters on a day-to-day basis is that work routinely involves substantial technological use, often related to technological production, across international boundaries. These workers merged technical skills, largely centered around communication and information technologies, and knowledge of their social environment to solve managerial and technical problems, create new markets and find alternative partners in their global enterprises. Hence we place the emphasis in this article on the knowledge workers themselves and their contexts, rather than on the new media sector as a distinct category.

Knowledge workers in high-tech industries, ranging from prototype machinists to CEOs 
(Chief Executive Officers), describe working within a web of connections. Some of these connections are face-to-face and reflect near daily interaction. Others are physically and socially distant and mediated by communications technologies, particularly the complex ecosystem of telephony and computer-based devices. The communications patterns have much in common. The interactions are intermittent and reciprocal. Flows of information, people, talent, money and material are necessary to get tasks done, whether those tasks are in the creation of technology or its distribution. Favors are asked that require extra effort, competence and reliability. These requests are often made under trying political and cultural circumstances. Internal competition and cultural differences make interdependent work more problematic. High-tech knowledge work is done by networks of interdependent global workers that must share information, act under severe time constraints, and establish effective relationships at a distance. In short, high technology work requires trust. Trust is not simply an affective or cognitive state of being, but an active tool that is used to manage and negotiate expectations between coworkers.

We used a comparative approach, a multi-site research design, to yield different research questions. Cross-site analysis allows us to see that differing social and technical infrastructures shape the way trust is built and maintained. Locating research sites in different locations also emphasizes the problematic nature of technologically-mediated relationships, since networks built at a distance and maintained virtually have risks that locally constructed networks do not. The management of interpersonal and organizational expectations that is embodied in the concept "trust" is an example of how locally constructed cultural realities are enacted on a global stage.

This article is drawn from ten years of ethnographic effort that has been, in part, directed toward understanding "silicon places"-globally interacting regions situated in places that have dominant economic focus on high technology industries, how such an economic focus plays out in social organization and cultural texture of the daily lives of people living in such regions. Our primary site has been Silicon Valley, in Northern California, home to least 8,000 officially constituted work organizations which are focused on a variety of high tech industries. Thirtyseven percent of Silicon Valley's gross regional product is from high tech (DeVol 1999: 55). This core of high tech workplaces has a halo of institutions subtly transformed by the presence of high tech. Technological metaphors and technologically informed problem-solving strategies dominate public discourse. Although Silicon Valley is the most robust and visible such community, other "silicon places" reflect the marriage of high-tech work and globalization. Dublin, Ireland has experienced an economic renaissance based of software production. As an English-speaking member of the European community, with connections to educated ethnic Irish around the world, Ireland has positioned itself to be key player in the world of knowledge work. Bangalore, India also harnesses the potential of software production. Its rich pool of technical elite, again English-speaking, initially made it ideal as a source of software production for multinational organizations. Expatriate Indians are socially and electronically linked to those who have gained experience in the corporate sector, form the basis of a new indigenous Indian 
technological domain (Saxenian 1999). The Taipei-Hsinchu corridor of Taiwan, while increasing involved in software localization for the Chinese market is primarily identified with or IT production. Taiwan's unique historic connection with Japan, as a former colony, and with the United States, adds to the cultural capital that can be used in developing its own economic infrastructure. Each silicon place uses its own distinctively local cultural history and demographic profile to create potentially useful connections to those who can serve as suppliers, capitalists, or markets. The relationships and interactions of the knowledge workers in each of these places are shaped by and shapes local identity and work practice.

Traditional anthropological tools such as in-depth ethnographic interview and participantobservation were used to investigate how technological saturation and global interaction is enacted in daily life. In one of the projects that informs this article, we conducted a series of ethnographic interviews and observations of workspaces with 175 people in Silicon Valley, each informant situated in a different kind of work, socioeconomic sector or cultural background. We sampled workers in a variety of workplaces, including @ Home Networks, Detente Technologies, Advanced Technical Staffing, Adobe Systems, Apple Computers, Cisco Systems, Daimler-Benz, Ericcson, Hewlett-Packard, Phoenix Computers, PeopleSoft and Xilinx, Knight Ridder's Mercury News as well as government and non-profit organizations. Only the first few of those organizations could be strictly classified as new media, but each one partakes of some aspect of the new economy. Daimler-Benz and Ericcson experiment with start-up-style workplace innovations. Although a mainstream newspaper, the Mercury News pioneered internet broadcasting and actively promoted new media. Cisco Systems, the "plumber of the internet" provided the infrastructure that supports new media. People we interviewed within Apple, Adobe, and Hewlett Packard use those organizations as safe havens between risky ventures. The purpose of that project was to explore the social realities experienced by high-tech workers, examine their material world, probe their social connections, and elicit beliefs and values to get an overview of work practices and their impact in daily family and community life (EnglishLueck et al. 2000; English-Lueck 2000).

This approach not only yielded descriptive information, but told us what various practices and artifacts meant to the people themselves. We used physical settings and projective techniques such as mapping "work spaces" and "networks" to elicit stories about relationships and daily work life. These stories not only provided rich descriptions, but also gave informants a chance to elaborate on the meaning of their daily practices. For example, when Irene, ${ }^{2}$ a diversity consultant in a major personal computer firm, drew a map of her work day, placing a giant telephone at the center of her world, she was making a symbolic statement about the supreme significance of technologically-mediated communication, as well as elaborating on the way she spent her time at work. We augmented this research with detailed examinations of fourteen dualcareer middle-class families in Silicon Valley, each family enduring hundreds of hours of participant and structured observations at work and at home. Several of those families contained workers in new media. Interestingly, the workers in such organizations were very much like 
high-tech workers from more traditional venues in their daily practices, and in fact they were connected to more traditional high-tech organizations as clients, former or future employers. In yet another project, under the auspices of the Institute for the Future we did fieldwork, primarily through in situ open-ended and semi-structured interviews, on work practices, social networks and global interconnections with 59 workers in four places identified as silicon placesBangalore, India, Taipei-Hsinchu, Taiwan, Dublin, Ireland, and Silicon Valley in the United States. The cross-cultural component allows us to elicit commonalities in global high-technology work and explore distinctive cultural and social differences. Participants in the project included new media organizations such as Arthur Anderson, a well-established consultant for the new economy, and internet and start-ups organizations such as Baltimore Technologies, Iona, Inforian, Zcom, and Magic Media. Other more traditional technology corporations-Gateway, IBM, Motorola, Novell, Irish Express Cargo, ISSI, Polaris Arvin Mills Limited, and Wiprowere still site of a distinctive work style that merged technologically-mediated work and global interconnections. The boundaries around new media eroded when we looked at the connections that organizations had with new media companies, and particularly with the relationships that workers had outside of their immediate employer. Polaris finances new media ventures in Taiwan; Irish Express Cargo develops innovative software to handle cargo shipping for new media products in Ireland as well as more antiquated material that must be moved from place to place.

\section{Interdependency and Trust}

Among the knowledge workers represented in our sample, informants described a world in which they gather and pass intellectual and material resources in order to do their work. Issues of trust emerge when successful work depends on the kindness of strangers. The social construction of that trust among knowledge workers in sites in Dublin, Taipei, Bangalore and Silicon Valley is the focus of this article. Research on work has been done and highlighting the importance of trust is not original to us (Barber 1983, Baba 1999; Douglas 1986; 1992). Douglas points out that merely having interdependent work is an insufficient reason for developing trust within an institution (1986: 55). Trust evolves as people engage in a complex symbolic dance, assessing and developing cultural constructions of risk, delineating objects of blame, and negotiating trust (Douglas 1992). Anthropologist Baba has examined the role of trust in hightech work, synthesizing the literature on workplace and trust and applying it to trust as it is constructed from different organizational positions within a high-tech workplace-managers, engineers, security and sales staff. She views trust as a function of the reciprocity that is part of interdependent work practice, and calls for an anthropological discussion of reciprocity in "transactions in which information itself is the object of exchange" (1999: 343). By focusing on the daily experience and social relations of knowledge workers in a comparative framework we can see the range of reciprocity-related processes that define trust-its inception, development, 
maintenance, and failure.

Trust is a psychosocial construction, defined as "the subjective expression of one actor's expectations regarding the behavior of another actor (or actors)" (Baba 1999: 333). We found it not only to be a manifestation of expectation, but a tactical management tool for manipulating expectations. Trust may be a demonstrated requirement of interdependent work, an intrinsic feature of high technology practice, but it is constituted differently in diverse contexts. The canon on workplace trust in the psychological literature, although culturally embedded in an American context, parses trust into five components that mirrored how our informants described the elements of trust: competence, consistency, integrity, interpersonal loyalty and openness, the latter more important in peer work relationships than in hierarchical ones (Schindler and Thomas 1993: 563). These components become especially problematic when enacted and communicated across cultural boundaries. An obvious example of this problem emerges when examining the schema for the component "competence." In Silicon Valley, at least in discourse if not in daily practice, there is a stated tolerance for failure. Failure, operationalized as a cancelled product or a bankrupt company, is not as grave in Silicon Valley as it would be in Taipei, where success and failure is bound up with mianzi, or "face," a concept that is culturally specific. In Silicon Valley the number of options for retreat, that is, getting another job, are more secure. If one company fails, there are literally thousands more to which one could apply. Moreover, the local culture of Silicon Valley invokes the concept of personal "reinvention," allowing people to build personal narratives in which they "learn from their mistakes," and thus "add value" to their individual competencies. However, there are fewer such practical options in Taipei and the Confucian legacy of "face" is derived from a personal narrative in which individuals can deliver a continuous pattern of hard work and success. How then would "competence" be differentially negotiated across those cultures? This is played out in multicultural teams in Silicon Valley where the free admission of possible prototyping errors or design flaws to quality assurance engineers is viewed with alarm by Taiwanese engineers, but as a necessary non-threatening procedure by an Israeli one. Beyond the differences in cultural construction, trust across cultures must reflect the social, economic and political realities of late capitalism. Silicon Valley can tolerate failure because its hegemonic position as the leading technological region has become relatively unquestioned. Bangalore faces other political legacies as a former colonial site. Power differences exist between organizations, regions and nations that make trust impractical. There are also inherent contradictions in trust relationships. Honest disclosure to a fellow engineer may build trust while the same disclosure to a customer insures failure. Trust is context dependentredefined in various interactions, with peers, customers, supervisors, and larger organizations.

The problems of common cultural constructions of trust are compounded when direct social information is limited-for example, when interactions are international and primarily mediated by information technologies. Establishing trust at a distance, in a vast virtual community requires social effort. If trust, as Baba persuasively indicates, is a function of balanced reciprocity — wherein favors are exchanged in a asynchronous, asymmetrical 
transaction with the expectation that future exchanges should be equivalent - then good intelligence about the trust partners is essential (Baba 1999: 335). Such intelligence gathering for establishing, building and maintaining trust is made both more convenient and more problematic by the use of technological mediated communications. Social and technical infrastructures shape the tools used in trust relationships. An infrastructure rich in media alternatives-exemplified by Silicon Valley-functions differently than one in which company sponsored E-mail is the only reliable method of communicating, an observation made in Bangalore.

As a tool for managing work-related expectations, trust is also intimately intertwined with time. Knowledge work in high-tech industries proceeds at different rhythms. Work is governed by the timing of activities, patterns that reflect "rhythms, cycles, beginnings, endings and transitions" (Barley 1988:125). Rhythms vary from the early stages of project work, to the compressed moments around milestones and deadlines. Relying on coworkers to deliver information "on time," particularly in when time is compressed, intensifies and defines "competence-based" trust - trust a kind of trust that is dependent on "effective" delivery of service (Baba 1999: 333; Barber 1983: 160-161). Because the interpersonal connections must be invoked for information exchange at various, and sometimes unpredictable, moments, the foundation for trust relationships is an ongoing process.

Each of informational interconnection must be anticipated and managed. In order to lay the groundwork for that exchange, a substantial amount of social work - initiating and nurturing relationships - must already be in place. Jeff, a software engineer tries to explain how his work gets done, drawing a verbal picture of a network of colleagues, some in his current company, others from past connections. Jeff says:

[The corporation's] products are large and complex enough — most products are, these days - that it's more than one person can do. A team is going to consist of marketing people who decide what features the product has to have or the new upgrade has to have, managers who try to schedule the time and decide what's feasible to do, engineers who do the coding, international people who do the translations into other languages, test people who do the testing, and tech writers do the manuals. There's a ton of people involved... Most of my time I spend on my own in my office working on my chunks of code, but there are two or three other people that I have to talk with and coordinate with on the code, including my manager. And the number of people I have to work with varies. Every so often I find I need someone's expertise that I haven't worked with before. I'll be talking to the QA [quality assurance] people more. I've been talking to the installer person a bit. Occasionally I have to talk to a marketing person. So it's kind of fuzzy... There's a once-a-week staff meeting for the product I'm working on that nearly everybody shows up at, and common issues are raised and discussed there. And then you use E-mail and voice mail and drop into the office 
for some of the other stuff. Voice mail and E-mail are really good because you don't have to find somebody in their office and free... And they there are others that I chat with when something of mutual interest comes up, but I don't keep them up to date on, you know, how the kids are doing in school, or anything. There aren't a whole lot of them, but a couple of them are very good friends, so they're worthy of mention...one of them is in upstate New York, another is on a farm in Minnesota, and one of them is a software developer in Perth, Australia.

Jeff goes on to elaborate that each year a year he throws a party at his house for his developer friends during an international software developer conference, especially those from other countries - thirteen hours of playful shop talk that sets up a year of virtual interactions. Mark, an MIS (management of information systems) specialist in a computer company, reinforces the need to build his interpersonal relationship across the global connections. In response to a question on where he works and what he does in those places, Mark elaborates:

I go to Taiwan and Tokyo every three, four months... Usually three or four days at each location... In Taiwan and Tokyo in the office itself it's usually around eight hours...usually there is two to three hours at each end for meetings...going to dinner with people there...the work, and socializing with people at work, talking about work, depending if you want to classify that as work... Am I sitting here with a paper and pencil doing a spreadsheet for work? "No." Am I talking and planning and establishing relationships with my workers? "Yes."... You have to. It's not an option. It's not an option if you're going to be successful.

This interdependence takes place among elite knowledge workers as well as their support staff. Andie, an admin in high tech, relates a story about the payoff that occurs when trust relationships are in place. She is responsible for scheduling and implementing meetings and trips. She consciously creates an aura of cordiality, learning names and asking about personal details. She tells how she once needed to get a piece of equipment to an airport, but could not find the right people. She says, "all the sudden, somebody came around and it's like "God sent them to me"... This is my idea of synergy. The people that I was trying to call, they just happened to come around with the type of equipment that I needed... when they saw that it was me, they said, "Oh, I'd be happy to help."

Meanwhile in Bangalore, Gurjinder, India a project manager in an international IT [information technology] firm discusses the scope of his network. He notes:

I connect to the other project managers and the customer, [the company's] project managers. I connect to the people, technical people. I connect to my own guys sitting there, international there... Plus sometimes I connect to some vendors, for example, tool vendors. I have to purchase tools, so I need to talk to those people. And then, I need to deal with my own people, my own managers. I deal with the 
business partner people they supply people to me... I need more skills I don't have, so I don't need them on my head count, I buy them, buy the people, the sources... I deal with a lot of people from [the corporation] internally [in Bangalore], who support me, like HR [human resources], finance, IS [information systems], business partner management people, the sourcing people, besides my team... And they're very important because, they don't report to me, but if they don't support me, I'm doomed... And then, many times, we use the customer's equipment, too, so we need to connect to their people to make sure that it works. And then, I deal with external customers here in India... I'm part of the CII, the Council of Indian Industries...that's a body of industry there, discussing the problems in India, Y2K problems, how can we help and suggest, comment, etc.

Gurjinder's comments point to the correlation between social networks and trust relationships. The networks act as a source for reciprocal relationships. However, the ambiguity of working within "weak" networks is problematic to building and nurturing trust relationships. Trusting someone to have the necessary "competence, consistency, integrity," as well as "loyalty" and "openness" is harder at a cultural and geographic distance. Global knowledge work necessitates working interdependently at a distance, a less than reassuring situation. Accurate prediction, an important feature of managing expectations, is made trickier. Anna, a multimedia division manager in Taipei noted:

You're information driven. Since you're co-working with other people, it's not just the Taiwan experience that will count. If I want to work with a designer in the US, I need to know how they work. It makes me, in terms of working-I feel constantly a lack of information. Because I need to work with people, not just in Taiwan but other areas. Those people are virtual... But my work partly relies on them. So it makes me feel a little less secure because you can't really see things. You can't control it.

Predictability is valued. Behaving as expected is a reassuring aspect of organizational life, part of building the trust relationship. Listening and responding to the needs of others, be they colleagues or customers, builds trust. Neal, a Dublin-based CEO of an indigenous Irish company, echoed this sentiment noting, "we appear to be listening to what they're saying...[and the customers] like the assurance that if anything were to go wrong they can always pick up the phone and know that we would react."

\section{Trust at a Distance}

The vastness of the global work also makes it difficult to establish an organizational presence. Interorganizational trust, not just interpersonal reciprocity, is another dimension to 
workplace trust relationships (Dodgson 1993: 78). Key to establishing that presence is developing a pattern of trustworthiness and reliability at the level of the organization. Mayfair, the co-founder of an IT company in Taipei reflects:

At first, we had the idea to be a global company but we didn't know how to do that. Because we didn't have any reputation. We didn't have any connections. We didn't have money at first. We only had technology. That's the only thing we had. So we tried to prove that we had very good technology. We cooperated with Microsoft, with IBM Taiwan...in the first year. After we proved that people can trust us, we had a very good reputation in Taiwan. Lots of very big companies looked at us and wanted to cooperate with us. So that was the beginning.

She goes on to reflect that global communications have shifted significantly with the advent of E-mail and Internet access. While telephone communications are still significant, Email makes multiple communications convenient. However it also poses problems. She notes, "If I send a file to you, you can send this file to others, forward it to others or cc it to others, so there are no secrets. You only can trust people that they won't do that...I should trust you, or I cannot send anything to you. We could not share anything." Inherent in group production practices is the need to share information, be it source code or budget restrictions. Prem, a project manager in Bangalore, notes: "We are the same engineering group. In an ideal situation, we should have a very high level of trust. We should be able to share everything." The act of openly sharing workrelated information is one way trust is constructed.

In the trust literature, there is a moral and affective component to trust that goes beyond predictability and demonstrated competence. In both Taipei and Silicon Valley there was a strong emotional component in the way trust was described. The Taiwanese talked of ganqing, cordiality and creating a level of "comfort" in interpersonal relationships. It is established by creating a network of known players that can be accessible to coworkers and customers. A known relationship can be the platform for trust while interacting with anonymous workers causes. This need to have a personal relationship, even if shallowly constructed, is magnified in the Silicon Valley interviews.

In Silicon Valley we asked workers to describe "a trustworthy person" and to give examples of how that trust was enacted, as well as how it could be violated. The discourse on trust carried a strong affective tone. Trust occurs when people "care" about each other and act out of motives other than self-advancement. This is the classic definition of a "fiduciary form of trust" in which there are expectations that "another will behave in a way that preserves and advances our interests while abstaining from opportunism” (Baba 1999: 333). The reasoning behind trust in Silicon Valley is remarkably coherent. Trust is designed to protect valuables both "physical and emotional." Building personal relationships is important beyond merely creating a history of professional reliability. Establishing confidentiality breeds trust. If a person divulges 
personal information, including opinions and perhaps even expressions of doubt about personnel and organizational foibles, then trust is established when those confidences are not divulged throughout the organization. Trustworthy colleagues do not hide direct criticisms, but do not air those criticisms publicly. Instead, they put a positive "spin" on possible mistakes.

To create that affective common ground effort is made to personalize culturally and technologically distant relationships. Part of building a sense of trust among strangers is to make them seem less strange. In Bangalore, Prem discussed what he did when he had to transfer his people to another distant team. Instead of merely communicating job specification, Prem tried to communicate more personal information to the new supervisor. He worked at conveying the social context - the engineers' "intra personal relationships" and working styles. This sensitive information is "locally confidential," and he hopes that the supervisors will rise to the occasion and understand the burden of trust placed on them. While he admits this strategy is not always successful, his objective in sharing this information to fellow managers is to achieve the necessary trust to complete the work.

In addition to the psychological components of trustworthiness, the moral reasoning behind trust embodies a series of work virtues. Technical competence is an obvious requirement. In many work practices punctuality and time consciousness are also noteworthy, particularly when finishing ones work is necessary for others to complete their tasks, especially across time zones. Waiting half a day in Dublin might delay an Australian counterpart's work for days. An ethic of accountability is cited. "Ownership" of work is lauded. People lay the groundwork for trust by taking responsibility for seeing a task through beyond the narrowly defined scope of work. This may mean crossing internal organizational boundaries or even going beyond the company to get information or to make sure a task is completed. Paramount in building a trust relationship in Silicon Valley is having "clean motives." It is assumed that politics exists and that people have agendas, but those agendas must not derail the working relationship.

Jaime, an engineer, lists three components to trustworthiness, echoing the psychological literature- "honesty and integrity and commitment." He goes on to elaborate that he has observed these features in coworkers, by "seeing how they handle customers." He adds:

Commitment is pretty straight forward. I mean they finish what they do.

Honesty — when you work with them, they tell you straight up how things are.

They are...given the politics factor, they are pretty much honest about achieving a task. And they are honest about helping to achieve that task. Integrity means that they only go so far to get the job done and if it means going outside the rules or demeaning someone else, they don't do it... They are committed to accomplishing a task within defined boundaries and do it in an open way."

Informants often found it difficult to recite a single episode of trust. It was the product of an incremental process. In contrast, there was no difficulty in retelling stories of specific 
incidents in which trust was broken. While many small events shaped the profile of a trustworthy soul, one episode defined an untrustworthy person. As Mary Douglas puts it, "Public memory is the storage system for the social order" (1986: 70). In this case, memories of success build into an amorphous whole, providing the basis for trust. In contrast, a single episode of trust betrayed is remembered vividly and embodied in the organizational memory. As Rupal, an Indian materials manager opines, "Trust is...built by [making] a commitment and meeting the commitment." Jeff, a software engineer in Silicon Valley, puts it this way:

Specific instances might be hard to come by, but I feel that I trust them because I know them well. I've worked with them before, smoothly and without friction, and productively. So it's less a particular occasion where someone has come through for me, than just years of, "Yeah, this person's been there a long time, and I've never had any trouble. When things happen this guy gets things done right." A popular phrase is, "This guy gets it."

Initializing trust is a tenuous and delicate process. The social context for creating trust was clearly different than the one for maintaining or building it. Technological mediation was one factor. We were told that jump-starting relationships through virtual media was viewed as a difficult, if not an impossible proposition. Reilly, a web designer in Dublin, notes:

You can't do that if the only communication you've had with them is an electronic one. Technology, I think, is brilliant for once relationships are in place. You can actually maintain those relationships. With initiating and getting to know someone there's no substitute for face to face contact... A lot of the signals are picked up from body language and the way a person looks at you and what not. You're never going to get that with technology. So you can't build up a true picture of their personality. Hence you won't be able to trust them until you sit in the same room with them.

Prem's voice adds, "In fact, E-mail actually complicates matters for these things. Sometimes when you're talking straight issues, people read [in] a lot of other things. For building trust and all these things, we have to meet or it doesn't happen... The trust never really gets built to a higher level." People think they have communicated effectively but lack the context to know they have made disastrous assumptions. Even a small amount of social context, developed over a dinner conversation or a pint of Guinness at the pub, can create a social contract for the suspension of distrust.

Learning personal context beyond the tasks of the moment is essential in maintaining the relationship once it is established. This is done in various ways. Face to face contact several times a year, "lunch" and "a real talk" affirm the relationship. Once the relationship is in place a quick task oriented note, that does not have to include the context or motive, "will" as Rajarshi notes, "cut short the communication." Even indirect intelligence can smooth the communication. 
Prem talks about accessing the Internet to understand the prevailing jokes made by his American counterparts. Otherwise, their references and social context are unintelligible and "I just miss it completely." Effective communication takes work.

Organizational context also plays a role in defining trust. In one Silicon Valley division, management had identified an organizational dysfunction and was undergoing organizational therapy. The division had gone through a long period of disregard for any potential problems in work processes, in the name of "harmony." This meant that people had politely ignored potential problems until they became hard to change. People in that organization defined trust as the honest disclosure of difficulties, a definition that generally did not spontaneously emerge in interviews. The construction of trust was specific to the local lore of that work site.

\section{Verifying, Manipulating and Derailing Trust}

Social identity plays a role in the verification of trust. In one Taiwanese IT company, Van, the CEO, noted that as a young Taiwanese person he did not symbolically convey confidence to potential customers and investors. Seniority is deeply valued in Chinese social organization so as a result they were planning to hire a middle-aged American figure-head CEO who would inspire the necessary trust.

Personal networks play a part in verifying trust interactions as well. In Taiwan, Anna, an IT worker, discusses how she gives her home phone number to "trusted clients." She also trusted her family members to screen the calls for her-knowing which ones to pass on to her and which ones to delay. In the observations of dual-career workers in Silicon Valley, spouses were repeatedly consulted to verify the credibility of individuals in work networks and their information. Rennie, an immigrant engineer in Silicon Valley, points out the artifacts of various projects he has worked on, highlighting the photos of the engineering team that seemed "like family" during a particularly grueling project. Family, and even co-workers turned fictive-kin, define, filter and test potential trust relationships.

Establishing trust also contains an element of cultural manipulation. Ryan, a quality assurance manager in an international organization, discussed how his Irishness created a link with his American counterparts. He capitalizes on the "memory" of Ireland possessed in popular culture writ large and Irish-Americans in particular, noting:

If you look at this little island that we have here, we call it the Island of Saints and Scholars, years and years ago, our culture lends itself to matching very, very well - we're almost chameleon like - to the American culture, and we can understand the American culture...and we can develop those relationships. And if you look at Ireland, for example, there's not that many Japanese companies here, 
but there's a hell of a lot of American companies here. And you [have to] ask yourself why is that? [Hewlett] Packard is here, Xerox is here, Intel, IBM, Motorola. [Dublin 12].

Tim, another Irish executive, speculates that the very powerlessness of Ireland makes it an ideal purveyor of trust in global business. He ruminates:

But this whole business, technology, information, security, the information age, has methods that you can do business in all of these arenas virtually shall we say, or using telecommunication technology. So, it provides great opportunities. And one of the things that we got to see going forward...is authenticating information. To authenticate anything, you always want to have it authenticated by a trusted method. I mean, we supply a product which issues digital certificates to individuals or people who want to trust each other. Networks of trust...somebody in Argentina,...if they want to do business with somebody in New Zealand, how do they actually verify their network of trust? How do they know? The guy in New Zealand may want to meet all of your family. It's a bit like the difference before you get married when you're meeting different potential partners. Some of them will want you to meet the parent's early. Some of them won't want you to meet the parents at all. And who makes the call?... I trust a 3rd party can do it... You could have a trusted 3rd party in a small country which is traditionally independent and neutral and no major allegiances at the cutting edge of technology, say, like Ireland, to act as that kind of hub for almost all global [ecommerce].

The flow of information that simultaneously necessitates and builds trust is not without disruptions and conflicts. Poor infrastructure may sabotage reliability, not matter how worthy the intentions. One manager in Bangalore discusses the need to establish trust and reliability in a climate where the post, the telephone system and transportation were unpredictable. Building trust included being able to predict or at least manage the failures of the system and find ways to communicate glitches to customers and coworkers. Building a network helped, but is not sufficient to make the post run on time, but is reduces the consequences of failure.

People move within and between organizations for a variety of reasons, including corporate reorganization, expansion and demise. Individual workers also may be promoted or simply job surf. This is particularly prevalent in Silicon Valley with its thousands of high tech organizations. International relocation poses particular problems in maintaining trust relationships. People disappear from the social network. However, those same people may reappear electronically and once again grant access to information, but that is not a given. 
Building social relationships to customers can be a tricky proposition. Tunjen, a manager in Hsinchu, Taiwan reflected on the inherent difficulty in information disclosure. He notes:

Because high speed networks develop very fast, we need to know the status of our company. I will collect the competitors' product information, test their products and generate our benchmark report. We will provide [two] benchmark reports. One is our inside reference and the other is [for] our customer. I will show [the customers] our advantage and then I will hide the report. [He laughs] I will hide the drawbacks and tell them "it's good, good, good, good, always it's good." But inside I will always [think] "drawback, drawback, drawback."

Open communications with customers also poses practical political and cultural difficulties. Realpolitik dictates diplomatic communications. When a customer from the People's Republic of China makes jokes to Taiwanese Tunjen about his "need to learn to swim," tacitly boasting about the naval superiority of the PRC, he keeps his peace. Tunjen notes, "The customer is 'first,' so we can say nothing." Trust must be constructed knowing the inequalities which creates barriers to be negotiated. For example, simply examining Silicon Valley "trust," as inherently multicultural as that community might be, would not have sensitized us to the role of national identity in forming trust - using Irishness or Chineseness to create an image of trustworthiness. Global economic and political power is a key factor in how trust is enacted and defined. Viewed only from Silicon Valley, currently the premier technological producercommunity, the effect of power would have been invisible, for it is taken for granted. The role of power is more easily seen from those who labor below.

Even if international politics do not interfere, corporate politics potentially sabotage trust relationships. Repeatedly our Silicon Valley informants warn us of the dangers of the "hidden agenda." Peter, a marketing program manager at a major Silicon Valley corporation, notes the inherent contradiction. People are constantly "in an environment where, myself included, we ARE selling [ourselves] all the time... We do have our agendas. We have our own goals. We all have our own things that we're working on." Yet those agendas must not undermine the network of reciprocal favors that support the trust building relationships.

In complex organizations with international components hidden agendas force a reaction of self-protection that sabotages trust. Ryan in Dublin notes, "[The other divisions] may have hidden agendas that may not suit what you're doing. Like if they were out for themselves, I'd be looking to do what's right for [the corporation in] Europe, here. If they were out for their own personal achievements and goals, then that's somebody else, you couldn't build the same level of relationship." Leah, a Silicon Valley admin, describes her relationship with her supervisor, a master of hidden agendas, "like one of those little slinky spiral things" that just keeps looping around preventing action. Sabotaging competent and effective production is a grave violation of work ethic embodied in trust. 
Another grim political reality overshadows the trust relationship of worker to organization. Downsized several times, Jeff notes that, "As much as a company likes to feel it's a big happy family - it's not a family, it's a business." That is a reality he has learned to accept. He cannot trust the organization to employ him, but he can hope they will act openly and responsibly in the inevitable betrayal.

Not all workers can maintain the complex dance of network building and trust maintenance. If enough violations occur, there is no public memory of incremental mutual supports to sustain trust. In Silicon Valley Chris notes matter-of-factly that he trusts no one except his cat and his computer. "It's not a concept that I have... My cat's about the only thing, my computer - they're trustworthy because if they break I know why. I can usually figure out they're going to break just on their own randomness. No, people... I don't see [trust] as a value in people. I don't hold that in esteem and at the same time I don't think I even look for it."

[Conclusion] 


\section{Endnotes}

1. This article is based on a presentation at the Society for Philosophy and Technology, 11th Biennial International Conference, July 16, 1999. San Jose, California, USA.

2. All informant names used in this article are pseudonyms.

\section{References}

Baba, M. (1999). "Dangerous Liaisons: Trust, Distrust, and Information Technology in American Work Organizations”, Human Organization 58: 331-346.

Barber, B. (1983). The Logic and Limits of Trust. New Brunswick, New Jersey: Rutgers University Press.

Barley, Stephen (1988). "On Technology, Time and Social Order: Technically Induced Change in the Temporal Organization of Radiological Work". In F. Dubinskas (ed.) Making Time: Ethnographies of High-Technology Organizations. Philadelphia, PA: Temple University Press. pp. 123- 169.

DeVol, R. (1999). America's High-Tech Economy: Growth, Development, and Risks for Metropolitan Areas. Santa Monica, CA: Milken Institute.

Dodgson. M. (1993). "Learning, Trust, and Technological Collaboration", Human Relations 46: 77-95.

Douglas, M. (1986). How Institutions Think. Syracuse, NY: Syracuse University Press.

Douglas, M. (1992). Risk and Blame: Essays in Cultural Theory. New York: Routledge. 
English-Lueck, J.A. (2000). "Work, Identity and Community in Silicon Valley." Final Report for Award 9810593. Washington, D.C., National Science Foundation.

English-Lueck, J.A., Darrah, C. and Freeman, J. (2000). Silicon Valley Cultures Project, available on-line http://www.sjsu.edu/depts/anthropology/svcp/.

Institute for the Future (1999). "Organizing for Innovation: Self-generating Webs". Proprietary document SR-672a. Menlo Park, Ca.

Saxenian, A. (1999). Silicon Valley's New Immigrant Entrepreneurs. San Francisco: Public Policy Institute of California.

Schindler, P. and Thomas, C. (1993). "The Structure of Interpersonal Trust in the Workplace," Psychological Reports 73: 563-573. 